\title{
İstanbul Bölgesinde Çalıșan İnşaat Firmalarında Proje Portföy Yönetimi Uygulamaları
}

\author{
Cenk BUDAYAN* \\ Y1ldız Teknik Üniversitesi, İnşaat Mühendisliği Bölümü, İstanbul \\ (Geliş/Received : 24.08.2016 ; Kabul/Accepted : 01.01.2017)
}

\begin{abstract}
ÖZ
Uluslararası proje sayısının artması ile beraber geleneksel olarak kullanılan her bir projenin kendi başına yönetilmesi yaklaşımının şirket başarısı için yeterli olmadığı görülmüsşür. Bunun sonucu olarak son yıllarda proje portföy yönetimi (PPY) anlayışı firmalar tarafindan uygulanmaya başlanmıştır. Bu yaklaşımda projelerin birbirine uyumlu hale getirilmesi ve kaynakların projeler arasında düzgün olarak atanmasıyla projelerin bir bütün olarak koordine edilmesi hedeflenmektedir. Literatüre bakıldığı zaman, PPY uygulamaları sayesinde firmaların performanslarını artırdıkları gözlenmiştir, fakat inşaat sektörü incelendiği zaman PPY uygulamasının sektörde çokta yaygın olmadığı görülmektedir. Bunun en önemli nedenlerinden biri, firmaların PPY'yi başarılı şekilde nasıl uygulayacaklarını ve uygularken karşılaşacakları engelleyicileri tam olarak bilememelerdir. Diğer önemli bir neden ise PPY uygulamasının ekstra emek ve kaynak gerektirmesi, fakat PPY faydalarının kısa sürede görülememesi ve uzun süreli yararların ise firmalar tarafında tam olarak idrak edilmemesi sonucu olarak kısa süre içerisinde PPY uygulamasından vazgeçilmesidir. Diğer bir deyişle, firmalar PPY'yi efektif olarak uygulayamadıkları ve uzun süreli yararları bilemedikleri için PPY uygulamasında başarısız olmaktadırlar, bu da PPY'nin yeterli düzeyde sektörde uygulanmasını engellemektedir. Bu çalışmada Türk inşaat firmalarının PPY uygularken karşıllaşabilecekleri sorunların ve uygulama sonucunda elde edecekleri başarıların ortaya çıkarılması için İstanbul bölgesinde yer alan Türk inşaat firmaları ile bir anket çalışması yapılmıştır. Böylece, PPY uygulamak isteyen firmalara kendilerine uygun bir yol haritası hazırlaması için gerekli altyapı sağlanmıștır. Ayrıca, PPY sonucunda elde edecekleri yararları bilmeleri onları PPY uygulamasına kaynak atama konusunda motive edecektir. Bu amaçla yapılan anket çalısması sonucunda en önemli engelleyiciler paydaşlar arasındaki fonksiyonel iletișim yetersizliği, paydaşların PPY uygulamasına adanmışlığındaki yetersizlik ve PPY uygulanması için gerekli olan eğitimlerdeki yetersizlikler olarak belirlenmiştir. En önemli etkiler ise kaynakların daha efektif kullanılması ve riskin azaltılması olduğu sonucuna varılmıştır.
\end{abstract}

Anahtar Kelimeler: Proje portföy yönetimi, uygulanmasını engelleyici faktörler, uygulamasının faydaları.

\section{Project Portfolio Management Applications for Turkish Construction Industry in Istanbul Region}

\begin{abstract}
With an increasing number of international projects, traditional project management which focuses on single project in isolation by assuming limited interactions among projects is not appropriate for being successful in the market. Therefore, a new project management method, namely project portfolio management (PPM) is started to be applied in the market. According to this method, the projects should be coordinated as a whole by establishing synergies among the projects and allocation of existing resources among the projects. Consequently, it is observed that the companies can increase their performance by applying the PPM effectively. However, the number of companies applying PPM in the construction industry is very limited. The one of the main reasons is that the companies have limited knowledge about how to apply the project portfolio management appropriately as well as the challenges confronted during this procedure. The other important reason is that the application of project portfolio management requires extra effort and resources, however most of the benefits are not observed in the short term and the long term benefits are not understood properly. Therefore, since the companies cannot apply the PPM effectively and do not recognize the long term benefits, the companies give up on applying the PPM implementation, which in turn limit PPM implementation in the market. To provide a deeper insight into the major challenges and benefits of the implementation and practice of PPM in construction industry, this paper conducts a questionnaire survey study by targeting Turkish construction companies working in Istanbul region. Therefore, the companies can exploit the findings of this study to develop a road map for applying PPM. In addition, the findings about the benefits can also be useful for the companies to motivate them. The most effective challenges obtained at the end of this study are lack of functional communication, lack of commitment of stakeholders and lack of required education. On the other hand, the most important benefits are effective allocation of resources and decrease of risk.
\end{abstract}

Keywords: Project portfolio management, challenges, benefits.

\section{GİRIŞ (INTRODUCTION)}

Proje portföy yönetimi (PPY) aynı stratejik amaçları hedefleyen ve aynı kaynaklar için mücadele eden projelerin

*Sorumlu Yazar (Corresponding Author)

e-posta: budayan@yildiz.edu.tr

Digital Object Identifier (DOI) : koordinasyonu ve kontrolü ile ilgilenmektedir [1]. Böylece, yöneticiler hangi projelere öncelik vereceklerine ve hangi projeleri şirket portföylerine dâhil edip hangilerini çıaracaklarına karar verebilmektedirler. Özellikle uluslararası is hacminin artmasıly beraber PPY daha da önem kazanmıştır. Fakat PPY uygulamaları bakıldığı za- 
man PPY'nin doğru projenin seçilmesi ile sınırlandırıldığ1 görülmektedir, bu durum da PPY'den şirketlerin efektif olarak yararlanmasını engellemektedir [2]. Aslına bakıldığı zaman PPY sadece projenin doğru seçilmesi ile ilgili değildir, ayrıca projelerin bir bütün olarak yönetilmesi, projeler arasında koordinasyonun sağlanması, projelerin birbiri ile uyumlu hale getirilmesi, projeler arasında kaynakların dağıtılması ile ilgilenmektedir [3]. Doğru bir PPY uygulamasının şirketlerin performanslarını pozitif yönde etkilediği ile ilgili birçok çalışma bulunmaktadır [4], fakat PPY'nin Türkiye'de ve dünyada özellikle inşaat sektörü içerisinde sınırlı şekilde uygulandı ğı görülmektedir. Bunun temel nedenlerinden biri inşaat firmalarının PPY'yi sadece doğru projeyi seçmek olarak görmesi ve diğer temel elemanlarını konusunda yeterli bilgiye sahip olmamalarıdır, diğer bir deyişle PPY'yi nasıl uygulayacakları konusunda sınırlı bilgilerinin olmasıdır. Diğer bir neden ise uygulama sırasında karşılaşılan sorunlar ve bu sorunlarla nasıl başa çıkılacağı ile ilgili bilgi yetersizliğidir [3]. Bu çalışma çerçevesinde, Türk inşaat sektöründe yer alan firmaların PPY uygulamaları incelenerek PPY'nin efektif olarak uygulanmasını engelleyici faktörler ortaya çıkarılmaya çalışılacaktır. Böylece, PPY'yi uygulamak isteyen firmaların PPY uygulaması sırasında karşılaşabilecekleri sorunlar ortaya çıkarılabilecek ve bu firmaların bu sorunlara karşı gerekli tedbirleri uygulamaya başlamadan alabilmeleri sağlanabilecektir. Diğer bir deyişle, firmalar portföy yönetimini uygulamaya başlamadan bu sorunlara göre kendi yol haritalarını oluşturabilecek ve böylece başarılı şekilde portföy yönetimi uygulamasını hayata geçirebileceklerdir. Bunun yanında, portföy yönetiminin firmalar tarafından uygulanmasını teşvik edecek önemli bir diğer nokta ise PPY uygulamasının avantajlarının bilinmesidir. $\mathrm{Bu}$ nedenle, bu çalışmanın diğer bir amacı efektif uygulanan PPY'lerin Türkiye'de uygulayan ve uygulamak isteyen inşaat firmalarına getirebileceği avantajları göstermektir. Böylece firmalar PPY'nin şirketlerinin ihtiyaçlarına cevap verebilme potansiyelini anlayabilecekler ve PPY'nin önemini daha iyi bir şekilde algılayacaklardır. Diğer önemli bir amaç ise PPY uygulamasının şirket içinde ne derecede başarılı bir şekilde uygulandığının ortaya çıkarılmasıdır. Bunun için PPY uygulayan firmaların başarıları, bir kriter olarak kullanılabilir. Bu çalışma sayesinde firmalar PPY uygulaması sayesinde diğer firmaların elde ettikleri başarıları ve gerçekleştirdikleri gelişmeleri görerek kendi uygulamalarının başarı seviyesini değerlendirebileceklerdir.

\section{KAVRAMSAL MODEL (CONCEPTUAL MODEL)}

Bu çalışmayı hayata geçirebilmek için ilk olarak kavramsal bir model geliştirilmeye çalışılmıştır. Bu modelin ilk kısmında PPY uygulayan firmaların PPY uygulama seviyelerinin ortaya çıkarması amaçlamaktadır. Bunu başarabilmek için PPY süreçleri ve anahtar PPY elemanlarını ortaya çıkarmak için yapılan çalışmalar irdelenmiş, bu analizler sonucunda 12 temel anahtar elemanı olduğu dikkate alınmıştır. Çalışmanın bu kısmı PPY uygulaması yaptığı söyleyen firmalara uygulanmıştır. $\mathrm{Bu}$ sayede PPY'nin firmalar arasında uygulama olgunluğu ortaya ç1karılmıştır. İkinci kısım ise PPY'nin uygulanmasının engelleyici faktörlerin ortaya çıkarılmasını hedeflemektedir. Bu amaçla geniş bir literatür taraması yapılmış, bu tarama sonucunda 11 negatif etkileyen faktör belirlenmiştir. Bu faktörler hem PPY uygulayan hem de uygulamayan şirketlere sorulmuş, böylece uygulayan firmaların ve uygulamayan firmaların PPY'nin uygulanmasını etkileyen faktörler konusundaki görüşleri ortaya çıkarılmıştır. Uygulayan firmalar açısından bakıldığı zaman bu kısım vasitasıyla uygulamada bu faktörlerin ne boyutta etkilediği konusunda fikir sahibi olunması hedeflenmiştir. Uygulamayan firmaların ise PPY'yi uygulamak istememesine neden olan faktörler gösterilmiștir. Son olarak PPY uygulaması sonucunda elde ettikleri kazanımlar ortaya çıkarılmaya çalışılmıştır. Bu amaçla PPY başarı kriterleri incelenmiş ve 9 tane başarı kriteri ortaya çıkarılmıştır.

\subsection{Proje Portföy Yönetiminin Anahtar Elemanları}

(Key Elements of Project Portfolio Management)

De Reyck ve diğ. [5] yaptıkları çalışma sonucunda 3 değişik adaptasyon seviyesi belirlemiş ve bu farklı seviyelerde yer alan firmaların PPY uygulamasından farklı şekilde etkilendiklerini göstermiştir. Bu çalışmanın gösterdiği çerçevede PPY uygulayan firmaların adaptasyon seviyesini gösterebilmek amacıyla PPY uygulamalarında kullanılması gereken anahtar elemanlar belirlenmiştir. Bu elemanları belirlemek için literatür taraması yapılmıştır. Rajegopal ve diğ. [6] 6 anahtar elemandan bahsederken De Reyck ve diğ. [5] 8 anahtar elemandan bahsetmektedir. Young ve Conboy [7] yaptıkları literatür çalışması sonucunda PPY ile ilgili kavramları 8 grup altında toplamışlardır. Bu çalışmalar incelendiği zaman ortak anahtar elemanlar gösterdikleri gibi, bazı anahtar elemanların ise çalışmaya özgün olduğu görülmüştür. $\mathrm{Bu}$ nedenle bu çalışmalardaki bütün anahtar elemanları kullanabilmek amacıyla çalışmalardan bahsedilen elemanlar birleştirilerek 12 anahtar elemandan oluşan bir liste elde edilmiştir. $\mathrm{Bu}$ elemanlar portföyde iletişim ve değişim yönetimi, proje portföyünün merkezi olarak yönetilmesi, finansal analizlerin yapılmas1, risk analizlerinin yapılması, bağlılıkların yönetilmesi, projelerin tanımlanması, kategorize edilmesi ve önemlerinin belirlenmesi, projelerin şirket stratejisine uygunluğunun sağlanması, projelerin sistematik olarak seçilmesi ve portföy dengesinin sağlanması, kısıtlamaların yönetilmesi, dinamik olarak portföyün tekrardan gözden geçirilmesi, portföy kaynak yönetimi ve özel bilgisayar programlarının kullanılmasıdir.

2.2. Proje Portföy Yönetiminin Uygulanmasını Engelleyici Faktörler (Challenges of Implementation of Project Portfolio Management)

De Reyck ve diğ. [5] bilgi teknolojileri projeleri için yaptıkları çalışmada PPY uygulaması sırasında karşılaşılan 11 önemli engelleyici belirlemişlerdir. Shehu ve Akintoye [3] ise inşaat sektörü için yaptıkları çalışmada 28 
tane engelleyici belirlemiş fakat daha sonra yaptıkları faktör analizi sonucunda bu 28 engelleyici değişkeni 6 temel faktörde incelemişlerdir. Elonen ve Artto [8] ise yaptıkları çalışma sonucunda proje seçimi ve PPY uygulaması sırasında şirketlerin karşılaştıkları 6 temel problemden bahsetmektedirler. Bu yapılan çalışmalar temel alınarak bu çalışmada 11 faktör belirlenmiştir. Bazı faktörler direkt olarak kullanılırken, bazı faktörler inşaat sektörü göz önüne alınarak değiştirilmiştir. Örneğin, De Reyck ve diğ. [5] üst düzey yönetimin PPY uygulamasına adanmışlığındaki yetersizliği önemli bir engelleyici olarak düşünürken bu çalışmada bütün paydaşların adanmışlığ 1 düşünülmüştür. Bunun nedeni ise firsatlardan yararlanabilmek için üst düzey yönetimden daha fazla birimin adanmışlığı ve desteği gerekmektedir [9]. Ayrıca, sadece üst yönetiminin PPY'ye adanmışlığının başarıya etkisi konusunda değişik fikirler bulunmaktadır [10]. Bazı yazarlar [11, 12] üst yönetimini proje portföye yönetime katkısının portföy performansı pozitif yönde etkilediğini söylerken, bazı yazarlar $[10,13]$ ise üst yönetimin dahil olmasının u-şeklinde bir etkisinin olduğunu iddia etmektedir. Bu yazarlara göre üst yönetiminin optimum seviyede dahil olması portföy performansını pozitif yönde etkilemektedir, fakat sürece çok fazla dahil olması ise proje portföy performansını negatif yönde etkileyebilmektedir. Bu nedenlerden dolayı sadece üst düzey yönetimin adanmışlığ incelenmesi bu faktör konusunda yeterli düzeyde fikrin elde edilmesine yetmeyecektir, bunun sonucu olarak bu faktör yerine tüm paydaşların adanmışlığı bu çalışma çerçevesinde incelenmiştir. Bu faktörler ve bu faktörlerin geçtiği çalışmalar Çizelge 1'de gösterilmiştir. değerlendirilmektedir. $\mathrm{Bu}$ kriterler maliyet, kalite ve zamandır. PPY'nin başarısının değerlendirilmesi sadece proje performansının değerlendirilmesi ile mümkün değildir ve daha geniş başarı kriterlerinin düşünülmesini gerektirmektedir [14]. Bu nedenle proje portföyünün şirketin başarısı üzerindeki etkileri incelenirken proje, portföy ve organizasyonun bir arada incelenmesi gerekmektedir. Cooper ve diğ. [15]'e göre, PPY performansı birbirinden farklı 4 boyutta incelenmelidir. Bunlar portföyde yer alan projelerin ortalama başarıları, portföyde yer alan projeler arasındaki sinerji, firmanın stratejisine uygunluk ve portföyün dengesidir. Müller ve diğ. [14] yaptıkları çalışmada 9 PPY performans değişkeni belirlemişlerdir. Belirledikleri boyutları üç ana grupta incelemişlerdir. Bu gruplar sonuçları elde etmek, amaçları başarmak ve öncelikleri dengelemektir. Teller [16] ise yaptığı literatür çalışması sonucunda proje portföy başarısını 7 boyutta toplamıştır. $\mathrm{Bu}$ boyutlar ortalama proje başarısı, ortalama ürün başarısı, projeler arasındaki sinerjinin kullanımı, stratejik uyum, portföy dengesi, geleceğe hazırlık ve ekonomik başarıdır. Diğer taraftan, PPY'nin şirketler üzerindeki etkileri Datz [17] tarafından 5 ana başlıkta toplanmıştır. Bunlar yatırımların değerlerinin risk azaltılırken maksime edilmesi, paydaşlar arasındaki iletişim ve uyumun güçlendirilmesi, yöneticilerin takım çalışmasına ve sorumluluk almaya yönlendirilmesi, planlama departmanlarının kaynakları daha efektif kullanarak zaman planlaması yapmasının sağlanması, gereksiz projelerinin sayısının azaltılması ve projelerin işinin bitirilmesinin kolaylaştırılmasıdır. Bu çalışmalardaki boyutlar incelenerek 9 PPY etkisi belirlenmiştir.

Çizelge 1. Literatür çalışması sonucunda elde edilen engelleyici faktörler (Challenges obtained as a result of the literature survey)

\begin{tabular}{llll}
\hline Faktörler & A & B & C \\
\hline Paydaşlar arasındaki fonksiyonel iletişim yetersizliği & $X$ & $X$ & \\
Bütün paydaşların proje portföy yönetimi uygulamasına adanmışlı̆ı̆ındaki yetersizlik & $X$ & $X$ & $X$ \\
Gerekli eğitim yetersizliği & $X$ & $X$ & \\
Proje portföy yönetimi teknikleri konusundaki bilginin yetersizliği & $X$ & $X$ & $X$ \\
Projeleri analiz etmek için gerekli verinin yetersizliği & $X$ & & $X$ \\
Proje yararlarının ölçülmesinde kullanılan uygun metotların eksikliği & $X$ & $X$ & $X$ \\
Şirketin açı bir stratejisinin olmaması & $X$ & $X$ & $X$ \\
Projelerin ve çalışan personelin finansal becerisinin yetersizliği & $X$ & $X$ & $X$ \\
Sik olarak proje kapsamının değişmesi & $X$ & $X$ & \\
Personel devinimi & $X$ & & $X$ \\
Ilk yatırım ve operasyon masrafları için gerekli bütçenin olmaması & & $X$ & $X$ \\
\hline
\end{tabular}

A: De Reyck ve diğ. [5], B: Shehu ve Akintoye [3], Elonen ve Artto [8]

2.3. Proje Portföy Yönetiminin Etkileri (The Impact of Project Portfolio Management)

Genel olarak firma başarılarının değerlendirilmesi proje bazında yapılmakta ve projeler üç temel kriter üzerinden
Belirlenen bu etkiler ve bu etkilerin geçtiği çalışmalar Çizelge 2'de gösterilmiştir. 
Çizelge 2. Literatür çalışması sonucunda elde edilen PPY'nin etkileri (The impacts of PPM obtained as a result of the literature survey)

\begin{tabular}{|c|c|}
\hline Etkiler & Referanslar \\
\hline Kaynakların daha efektif kullanılması & Meskendahl [18], Chao ve diğ. [19] \\
\hline Riskin azaltılması & Teller [16], Mikkola [20], Chao ve diğ. [19] \\
\hline $\begin{array}{l}\text { Proje Portföyündeki dengenin } \\
\text { sağlanması }\end{array}$ & Hunt ve diğ. [21], Cooper ve diğ. [15], Jonas ve diğ. [22], Teller [16] \\
\hline Firma stratejisine uygun hale gelinmesi & Hunt ve diğ. [21], Cooper ve diğ. [15], Jonas ve diğ. [22], Teller [16] \\
\hline Belirlenen ortalama maliyeti başarmak & Meskendahl [18], Jonas ve diğ. [22], Müller ve diğ. [14] \\
\hline Belirlenen ortalama zamanı başarmak & $\begin{array}{l}\text { Hunt ve diğ. [21], Meskendahl [18], Jonas ve diğ. [22], Müller ve } \\
\text { diğ. [14] }\end{array}$ \\
\hline $\begin{array}{l}\text { Yöneticilerin takım çalışmasına ve } \\
\text { sorumluluk almaya yönlendirilmesi }\end{array}$ & Jonas ve diğ. [22], Teller [16], Cooper ve diğ. [15] \\
\hline Belirlenen ortalama kaliteyi başarmak & Meskendahl [18], Jonas ve diğ. [22], Müller ve diğg. [14] \\
\hline $\begin{array}{l}\text { Paydaşlar arasındaki iletişimin } \\
\text { geliştirilmesi }\end{array}$ & Teller [16], Jonas ve diğ. [22] \\
\hline
\end{tabular}

\section{ARASTIRMA YÖNTEMİ (RESEARCH METHODOLOGY)}

Çalışmanın hedeflerini yerine getirmek amacıyla bir anket hazırlanmıştır. Hazırlanan anket 4 kısımdan oluşmaktadır. İlk kısımda anketi cevaplayan kişiler ve çalış̧ıkları firmalar hakkında bilgi elde etmek amacıyla 8 soru sorulmuştur. Bu kısmın amacı ankete katılan kişilerin ve çalıștıkları firmaların bu anketi cevaplayabilme yeterliliğini ortaya çıkarmaktır. Sonuç olarak bu çalışma ankete dayalı olarak yapılmaktadır ve ankete dayalı çalışmaların güvenirliliği anketi cevaplayan kişilerin yeterliliği ile sağlanabilmektedir. İkinci kısım PPY’nin 12 temel elemanından oluşmaktadır. Ayrıca, bu kısmın sadece PPY uygulayan firmalar tarafindan cevaplandirılması gerekmektedir, bu nedenle ankete katılan firmalara PPY uygulama durumları sorulmuş ve bu cevaba göre ankete katılanların yönlendirilmesi yapılmıştır. Diğer bir deyişle, bu kısım toplam 13 sorudan oluşmaktadır ve bu sorulardan anahtar elemanlarla ilgili sorular sadece PPY uygulayan firmalar tarafindan cevaplandırmıştır. Anketin bu kısmında anketi cevaplayanlara bu elemanları kullanıp kullanmadıkları sorulmuştur. Anketin üçüncü kısmı ise PPY'nin başarılı şekilde uygulanmasını engelleyici 11 faktörden oluşmaktadır. Bu faktörler anketi cevaplayanlar tarafından 1-5 Likert ölçeğinde değerlendirilmektedir. Bu değerlendirmede 1 çok az anlamına gelirken 5 çok fazla anlamına gelmektedir. Anketin son kısmında ise PPY'nin iş süreçlerine olan etkileri değerlendirilmiştir. Bu kısımda bir önceki kısımda olduğu gibi 1-5 Likert ölçeği kullanılmış ve değerlendirme 1 ile 5 arasında yapılmıştır. Bu çalışma için hazırlanan anket farklı firmalarda çalışan karar verici konumunda bulunan 135 kișiye e-posta ve telefonla iletişime geçilerek gönderilmiştir. Katılımcılar seçilirken sadece PPY uygulanan firmalar hedef olarak belirlenmemis, ayrıca uygulamayan firmalar da seçilmiştir. Böylece, uygulayan ve uygulamayan firmaların PPY konusundaki görüşlerinin alınması sağ- lanmıştır. Gönderilen anketlerden 48 tanesinden geri dönüş alınmış̧ır. Sonuç olarak yapılan çalışmada dönüş oran1 $\% 35,56$ olarak gerçekleşmiştir.

\section{ANALIZZLERIN İRDELENMESI (DISCUSSION OF ANALYSES)}

Anketin her bölümü tanımlayıcı analizle incelenmiş ve elde edilen sonuçlar aşağıda yer alan başlıklarda irdelenmiştir.

\subsection{Ankete Katılanların ve Calıștıkları Sirketlerin \\ Demografik Yapısı (Demographic Structure of the} Participants and their Companies)

$\mathrm{Bu}$ ankete yer alan katılımcıların ve çalıştıkları firmaların demografik yapısı aşağıdaki çizelgede gösterilmiștir. Bu çizelge incelendiği zaman ankete katılan kişilerin büyük kısmının $(\% 39,58)$ yönetim içerisinde görevli olduğu görülmektedir. Ayrıca iş geliştirme ve planlama departmanlarında çalışan kişilerin bu çalıșmada temsil edildikleri söylenebilir. Yine tecrübeleri ile ilgili bilgiler incelendiği zaman bu ankete katılanların büyük kısmının 10-15 yıl arasında $(\% 45,83)$ sektör tecrübesine sahip olduğu görülmektedir. Bu veriler 1şı̆̆ıında ankete katılan kişilerin sektör içerisindeki deneyimlerinin yeterli seviyede olduğunu söylenebilir. Firmalarla ilgili bilgilerden yararlanarak, ankete katılan firmaların büyük çoğunluğunun orta $(\% 43,75)$ ve büyük ölçekli $(\% 35,42)$ firmalar olduğu anlaşılmaktadır. Ayrıca, şirketlerin faaliyette bulundukları y1l sayısı da bu firmaların deneyim anlamında yeterli seviye olduğunu göstermektedir. İș hacmine bakıldığı zamanda şirketlerin iş hacminin yüksek olduğu söylenebilir. En son olarak uzmanlaştıkları proje tiplerinde ise bütün proje tiplerinin aynı oranda bu çalışmada temsil edildikleri görülmektedir. Bu bulgular çerçevesinde ankete katılan firmaların bu çalışma içerisinde yer alacak deneyim ve büyüklüğe sahip oldukları söylenebilir. 
Çizelge 3. Katılımcıların ve çalıştıkları şirketlerin demografik yapısı (Demographic structure of the participants and their companies)

\begin{tabular}{|c|c|c|c|c|c|}
\hline $\begin{array}{l}\text { Çalıştıkları } \\
\text { Şirketin } \\
\text { Büyüklü̈ğü }\end{array}$ & \multicolumn{2}{|c|}{ Küçük } & Orta & \multicolumn{2}{|r|}{ Büyük } \\
\hline \multirow{2}{*}{$\begin{array}{l}\text { Çalışılan } \\
\text { Departman }\end{array}$} & \multicolumn{2}{|c|}{ Yönetim } & İş geliştirme & \multicolumn{2}{|c|}{ Planlama } \\
\hline & \multicolumn{2}{|c|}{$\% 39,58$} & $\% 33,33$ & \multicolumn{2}{|r|}{$\% 27,08$} \\
\hline \multirow[t]{2}{*}{ Tecrübesi } & $1-5$ yil & $5-10$ & $10-1$ & $\begin{array}{c}15-20 \\
\text { y1l }\end{array}$ & $>20 \mathrm{y} 1 \mathrm{l}$ \\
\hline & $\% 6,25$ & $\% 31$, & $\% 4$ & $\% 6,25$ & $\% 8,33$ \\
\hline \multirow{2}{*}{$\begin{array}{l}\text { Şirkette çalışan } \\
\text { sayısı }\end{array}$} & $1-9$ & $10-25$ & $25-50$ & $50-100$ & $100+$ \\
\hline & $\% 47,92$ & $\% 25,00$ & $\% 12,50$ & $\% 2,08$ & $\% 12,50$ \\
\hline \multirow{2}{*}{$\begin{array}{l}\text { Şirketin faaliyette } \\
\text { bulunduğu süre }\end{array}$} & $1-5$ & $5-10$ & $10-20$ & $20-30$ & $30+$ \\
\hline & $\% 25,00$ & $\% 12,50$ & $\% 41,67$ & $\% 10,42$ & $\% 10,42$ \\
\hline \multirow[t]{2}{*}{$\begin{array}{l}\text { Şirketin yıllık } \\
\text { cirosu }\end{array}$} & $\begin{array}{c}\text { 0-1 } \\
\text { milyon } \\
\text { dolar }\end{array}$ & $\begin{array}{l}\text { 1-5 milyon } \\
\text { dolar }\end{array}$ & $\begin{array}{l}\text { 5-10 milyon } \\
\text { dolar }\end{array}$ & $\begin{array}{l}\text { 10-20 } \\
\text { milyon } \\
\text { dolar }\end{array}$ & >20 milyon dolar \\
\hline & $\% 18,75$ & $\% 25,00$ & $\% 29,17$ & $\% 16,67$ & $\% 10,42$ \\
\hline \multirow[t]{2}{*}{$\begin{array}{l}\text { Uluslararası } \\
\text { pazardaki cirosu }\end{array}$} & $\begin{array}{c}\text { 0-1 } \\
\text { milyon } \\
\text { dolar }\end{array}$ & $\begin{array}{l}\text { 1-5 milyon } \\
\text { dolar }\end{array}$ & $\begin{array}{l}\text { 5-10 milyon } \\
\text { dolar }\end{array}$ & $\begin{array}{l}\text { 10-20 } \\
\text { milyon } \\
\text { dolar }\end{array}$ & >20 milyon dolar \\
\hline & $\% 47,91$ & $\% 25,00$ & $\% 12,50$ & $\% 12,50$ & $\% 2,08$ \\
\hline \multirow{2}{*}{$\begin{array}{l}\text { Uzmanlaştığ } \\
\text { proje tipleri }\end{array}$} & $\begin{array}{c}\text { Konut } \\
\text { projeleri }\end{array}$ & $\begin{array}{c}\text { Endüstriyel } \\
\text { projeler }\end{array}$ & \multicolumn{2}{|c|}{$\begin{array}{l}\text { Altyapı } \\
\text { Projeleri }\end{array}$} & Diğerleri \\
\hline & $\% 35,42$ & $\% 18,75$ & \multicolumn{2}{|c|}{$\% 33,33$} & $\% 12,5$ \\
\hline
\end{tabular}

4.2. Bu Çalışmaya Katılan ve PPY Uygulayan Firmaların Olgunluk Seviyeleri (The Maturity Level of the PPM Applying Companies in this Study)

Ankete katılan firmaların \%75'lik kısmı PPY'i uygulamadıklarını belirtmişlerdir. $\mathrm{Bu}$ da ankete katılan 12 firmanın PPY'i uyguladıkları anlamına gelmektedir. Fakat Çizelge 4'deki veriler incelediği zaman PPY'nin anahtar elemanlarının çoğunluğunun bu firmalar tarafından yoğun olarak kullanıldığı anlaşılmaktadır. Bu da uygulayan firmaların uygulama anlamında yüksek bir olgunluğa sahip olduğunu göstermektedir. Her ne kadar firmalar bu elemanları kullandıklarını deklare etseler de önemli bir nokta da bu elemanların hangi seviyede kullanıldı̆̆ 1 ve elde edilen sonuçların firmalar tarafindan ne ölçüde dikkate alındığıdır. Çizelge 4 incelendiği zaman en yüksek uygulama yüzdelerinin proje seçimiyle ilgili uygulamalarda olduğu görülmektedir. Bu durum ankete katılan Türk inşaat firmalarının en önde tuttukları
PPY elemanlarının proje seçimleri ile ilgili olduğunu göstermektedir. $\mathrm{Bu}$ da Kaiser ve diğ. [2] tarafindan belirtildiği gibi firmaların hala PPY'i bir planlama ve kontrol yaklaşımı olarak gördüklerini göstermektedir. $\mathrm{Bu}$ anahtar elemanlar arasında en düşük uygulama yüzdesinin özel bilgisayar programlarının kullanılmasında olduğu görülmektedir. De Reyck ve diğ. [5] tarafından yapılan çalışmada da çalışmaya katılan firmaların sadece \%30'nun PPY için geliştirilmiş programları kullandıkları görülmektedir. Bu çalışmada dikkat çeken diğer önemli bir bulgu ise, proje portföylerinin merkezi olarak yönetiminin sınırlı olduğudur. Hâlbuki PPY için merkezi bir yönetim ihtiyacı literatürde geniş olarak belirtilmiştir [23]. Özellikle, bilginin merkezi bir veri tabanında toplanması, bilgi akışı için büyük bir öneme sahiptir [8]. De Reyck ve diğ. [5] tarafından yapılan çalışma incelendiği zaman bu anahtar elemanın uygulama oranın $\% 93$ olduğu görülmektedir. 
Çizelge 4. PPY anahtar elemanlarının PPY uygulayan firmalarda uygulanma olgunluğu (The maturity level of PPM key elements in firms applying PPM)

\begin{tabular}{|c|c|c|}
\hline Anahtar elemanlar & $\begin{array}{c}\text { Uygulanma } \\
(\%)\end{array}$ & $\begin{array}{c}\text { Uygulanmama } \\
(\%)\end{array}$ \\
\hline Portföye iletişim ve değişim yönetimi & 83,33 & 16,67 \\
\hline Proje portföyünün merkezi olarak yönetilmesi & 50,00 & 50,00 \\
\hline Finansal analizlerin yapılması & 91,67 & 8,33 \\
\hline Risk analizlerinin yapılması & 83,33 & 16,67 \\
\hline Bağlılıkların yönetilmesi & 58,33 & 41,67 \\
\hline Projelerin tanımlanması, kategorize edilmesi ve önemlerinin belirlenmesi & 75,00 & 25,00 \\
\hline Projelerin şirket stratejisine uygunluğunun sağlanması & 75,00 & 25,00 \\
\hline Projelerin sistematik olarak seçilmesi ve portföy dengesinin sağlanması & 83,33 & 16,67 \\
\hline Kisıtlamaların yönetilmesi & 66,67 & 33,33 \\
\hline Dinamik olarak portföyün tekrardan gözden geçirilmesi & 75,00 & 25,00 \\
\hline Portföy kaynak yönetimi & 75,00 & 25,00 \\
\hline Özel bilgisayar programlarının kullanılması & 33,33 & 66,67 \\
\hline
\end{tabular}

\subsection{PPY Anahtar Elemanları ile İlgili Analizler (PPM} Key Elements Analyses)

Çalışma sonunda elde edilen engelleyici faktörlerle ilgili veriler tanımlayıcı analiz yöntemi (descriptive analysis) kullanılarak irdelenmiş ve elde edilen sonuçlar Çizelge 5 'te gösterilmiştir. Çizelge 5'te ankete cevap verenlerin verdikleri cevapların ortalaması ve bu cevapların standart sapmaları gösterilmiştir. Çizelge 5 incelendiği zaman bütün faktörlerin ortalamalarının 3 üzerinde yer aldığı görülmektedir. Bu da belirlenen bütün faktörlerin PPY'nin başarılı şekilde uygulanabilmesini engeleyebilme potansiyelinin olduğunu göstermektedir. Fakat bu faktörler içerisinde özellikle paydaşlar arasındaki fonksiyonel iletişim yetersizliğinin, paydaşların PPY uygulamasına adanmışlığındaki yetersizliğinin ve gerekli eğitim yetersizliğinin PPY'nin başarılı şekilde uygulanmasında diğerlerine göre daha etkili olduğu görülmektedir. $\mathrm{Bu}$ faktörler incelendiği zaman paydaşların PPY'de önemli bir role sahip olduğu söylenebilir. Özellikle paydaşlar arasındaki fonksiyonel iletişimin yetersiz olması PPY'nin başarılı şekilde uygulanmasında en büyük engel olarak görülmektedir. Sonuç olarak PPY bütün projelerin ortak bir hedef ulaşmak için firma kaynaklarının en optimum seviyede kullanılmasını hedeflemektedir. Bu da iyi bir iletişimle mümkün olabilmektedir [24, 25]. Ayrıca, PPY'nin uygulanabilmesi için gerekli olan temel elemanlardan projelerin birbirine olan bağımlılıklarının belirlenmesi ancak açık bir iletişimle mümkündür [26]. Son olarak, özellikle yöneticiler arasındaki açık bir iletişimin olması proje portföyünü yönetmek için gerekli olan bilgilerin güvenirliliği ve şeffaflığı sağlamaktadır [22]. Her ne kadar iyi bir PPY için paydaşlar arasındaki iletişimin önemi yukarıda gösterildiği gibi literatürde belirtildiyse de inşaat sektörüne bakıldığı zaman inşaat sektörünün özgün yapısından dolayı paydaşlar arasındaki iletişimin yeterli olmadığı görülmektedir. Shehu ve Akintoye [3] Birleşik Krallık inşaat sektörü için yaptıkları çalışmada fonksiyonel iletişim yetersizliğini 3,759 ortalama ile önemli bir faktör olarak belirlemekle beraber önem derecesi diğer faktörlere göre daha aşağıda yer almaktadır. Diğer taraftan, bu çalışma ise iletişim eksikliğini 4,630 ortalama değer ile en önemli faktör olarak göstermektedir. Bu da bu çalışmaya katılan firmalar açısından Birleşik Krallık inşaat sektörüne göre iletişim konusunda Türk inşaat sektörünün daha yetersiz olduğu anlaşılmaktadır. Elde edilen çıktı sonucunda PPY'nin uygulanmasında fonksiyonel iletişim yetersizliğinin Birleşik Krallık inşaat sektörüne göre Türk inşaat sektörü için daha önemli bir engelleyici olduğu sonucuna varılabilir.

İkinci en önemli faktör ise paydaşların PPY uygulamasına adanmışlıklarında gösterdikleri yetersizliktir. PPY'nin başarısına, adanmışlığın iki şekilde etki ettiği söylenebilir. Birinci olarak, PPY zaman ve kaynak gerektiren bir süreçtir, ayrıca edinimleri uzun bir süreçten sonra görülmektedir. Diğer bir deyiş yapılan yatırımın etkileri uzun bir zaman sonunda görülmektedir. Adanmışlığın yüksek seviyede olmadığı durumlarda firmalar PPY için gerekli kaynağı atamakta çekimser kalmakta ve PPY uygulamasında vazgeçerek başarısız olunmasına neden olmaktadırlar [11]. Diğer taraftan, firmalar tekil proje yönetiminden PPY'ye geçerken yönetimsel süreçlerini tamamen değiştirmektedirler. $\mathrm{Bu}$ da paydaşların bu değişime kendilerini adapte etmesini gerektirir. $\mathrm{Bu}$ durum, paydaşlar için yeni zorlukları da beraberinde getirmektedir. Bu zorlulukların aşılması ancak paydaşların kendilerinin PPY'ye inanması ile mümkün olabilmektedir. Farklı sektörler için yapılan çalışmalarda da üst yönetiminin en azından optimum katkısının PPY'nin 
başarısı için elzem olduğunu göstermiştir. Fakat özellikle inşaat sektörü için yapılan çalışmalarda bu faktör diğer faktörlere göre daha önemli bulunmuştur. Shehu ve Akintoye [3]'nin Birleşik Krallık inşaat sektörü için yaptıkları çalışmada en önemli engelleyici faktörün iş liderlerinin PPY'ye olan adanmışlıklarının yetersiz olması olduğunu belirlemişlerdir. Bu da bize inşaat sektörünün yapısı dolayısıyla bütün paydaşların adanmışlığının PPY'nin başarısı için çok önemli olduğunu göstermektedir.

Diğerlerine göre daha etkisiz olarak görülen faktör ise ilk yatırım ve operasyon masrafları için gerekli bütçenin olmaması olarak belirtilmiştir. Shehu ve Akintoye [3]'nin çalışmasında da yatırım için gerekli olan ekstra bütçe önem olarak orta sıralarda yer almıştır. Özellikle proje portföy yönetimi uygulamayan firmalar proje portföy yönetimi için gerekli bütçeden daha çok proje portföy yönetimini uygulamak için gerekli bilgiyi ve eğitimin daha önemli birer faktör olduğunu belirtmişlerdir. $\mathrm{Bu}$ da firmaların maddi nedenlerden daha çok proje portföy yönetimini nasıl uygulayacaklarını bilmediklerinden kaynaklı olarak proje portföy yönetiminden uzak durduklarını göstermektedir.

$\mathrm{Bu}$ çalışma çerçevesinde PPY'yi uygulayan ve uygulamayan firmaların engelleyici faktörler üzerindeki görüş farklılıklarını ortaya çıkarabilmek için SPSS 22 programı kullanılarak t-testi uygulanmıştır. $\mathrm{Bu}$ analiz sonucunda
PPY uygulayanların ve uygulamayanların verdikleri cevapların ortalamaları elde edilmiş, ayrıca analiz sonucunda elde edilen p-değeri de çizelgede gösterilmiştir. Pdeğeri istatiksel olarak iki grup arasında anlamlı bir görüş farkının mevcudiyetini test etmek amacıyla kullanılır. Eğer p-değeri 0,05'ten daha küçük bir değere sahip ise bu iki grup arasında anlamlı bir görüş farkının olduğu anlaş1lır. Uygulayan ve uygulamayan firmaların bu faktörler hakkındaki görüşlerinin ortalamaları ve p-değerleri Çizelge 5'de gösterilmektedir. Bu değerler incelediği zaman en önemli ve istatistiksel olarak tek anlamlı görüş farkının gerekli eğitim yetersizliğinde $(p$-değeri $=0,046)$ olduğu görülmektedir. Uygulamayan firmalar bunun çok önemli bir engelleyici olduğunu düşünmektedir, buna karşı uygulayan firmalar ise önem olarak bu faktörü daha alt sıralara koymaktadır. Diğer önemli bir görüş farklılığ ise proje portföy yönetimi teknikleri konusundaki bilginin yetersizliği (p-değeri = 0,091) faktöründe görülmektedir. Bu iki faktörde göstermektedir ki proje portföy yönetimini uygulamayan firmalar proje portföy yönetimi için yeterli eğitimin ve bilginin elde edilmesinin zor olduğunu düşünmekte ve bunun PPY uygulamasını çok zor hale getirdiğine inanmaktadır. Diğer taraftan uygulayan firmalar ise bu durumun aşılabilir olduğu düşünmektedir, bu nedenle bu faktörleri daha az etkili bir faktör olarak görmektedir. $\mathrm{Bu}$ durum uygulamayan firmaların proje portföy yönetimi konusunda sınırlı bilgilerinin olduğunu

Çizelge 5. Engelleyici faktörler için elde edilen tanımlayıcı analiz ve t-test sonuçları (Descriptive statistics and t-test results of challenges)

\begin{tabular}{|c|c|c|c|c|c|}
\hline Engelleyeci faktör & Ortalama & $\begin{array}{l}\text { Std. } \\
\text { sapma }\end{array}$ & $\begin{array}{c}\text { PPY } \\
\text { uygulayan }\end{array}$ & $\begin{array}{c}\text { PPY } \\
\text { uygulamayan }\end{array}$ & P-değeri \\
\hline $\begin{array}{l}\text { Paydaşlar arasındaki fonksiyonel iletişim } \\
\text { yetersizliği }\end{array}$ & 4,63 & 0,704 & 4,60 & 4,63 & 0,899 \\
\hline $\begin{array}{l}\text { Bütün paydaşların proje portföy yönetimi } \\
\text { uygulamasına adanmışlığındaki yetersizlik }\end{array}$ & 4,50 & 0,960 & 4,50 & 4,50 & 1,000 \\
\hline Gerekli eğitim yetersizliği & 4,45 & 0,986 & 3,82 & 4,66 & 0,046 \\
\hline $\begin{array}{l}\text { Proje portföy yönetimi teknikleri } \\
\text { konusundaki bilginin yetersizliği }\end{array}$ & 4,33 & 0,917 & 3,90 & 4,46 & 0,091 \\
\hline $\begin{array}{l}\text { Projeleri analiz etmek için gerekli verinin } \\
\text { yetersizliği }\end{array}$ & 4,28 & 1,037 & 3,90 & 4,40 & 0,190 \\
\hline $\begin{array}{l}\text { Proje yararlarının ölçülmesinde kullanılan } \\
\text { uygun metotların eksikliği }\end{array}$ & 3,98 & 1,165 & 3,90 & 4,00 & 0,818 \\
\hline Şirketin açık bir stratejisinin olmaması & 3,48 & 1,300 & 3,70 & 3,40 & 0,553 \\
\hline $\begin{array}{l}\text { Projelerin ve çalışan personelin finansal } \\
\text { becerisinin yetersizliği }\end{array}$ & 3,48 & 1,395 & 3,70 & 3,40 & 0,563 \\
\hline Sık olarak proje kapsamının değişmesi & 3,33 & 1,206 & 3,40 & 3,30 & 0,823 \\
\hline Personel devinimi & 3,20 & 0,939 & 3,00 & 3,26 & 0,444 \\
\hline $\begin{array}{l}\text { Illk yatırım ve operasyon masrafları için } \\
\text { gerekli bütçenin olmaması }\end{array}$ & 3,08 & 1,575 & 3,40 & 2,96 & 0,458 \\
\hline
\end{tabular}


ve bu nedenle proje portföy yönetimi uygulamaktan çekindiğini göstermektedir. Hâlbuki görüleceği gibi bu engel PPY uygulayan firmalar tarafindan aşılabilecek bir engel olarak görülmektedir. Bu da göstermektedir ki PPY uygulamayan firmalar bu konu hakkında sınırlı bilgileri olduğu için PPY uygulamaktan kaçınmaktadırlar.

\subsection{Ankete Katılan Firmaların PPY'nin Etkisi \\ Üzerindeki Görüşleri (Opinions of the \\ Participating Companies on the Impacts of PPM)}

Ankete katılan firmaların PPY uygulamasının etkisi hakkındaki görüşleri ile ilgili yapılan tanımlayıcı analiz ve portföy yönetimi uygulayan ve uygulamayan firmaların bu konu üzerindeki görüş farklılıklarını görebilmek için yapılan t-test sonuçları Çizelge 6'da gösterilmiştir. $\mathrm{Bu}$ çizelge incelendiği zaman ankete katılan firmaların PPY uygulamasının Türk inşaat firmaları üzerinde pozitif etki yapacağını düşündükleri görülmektedir. Fakat etki faktörleri incelendiği zaman, özellikle inşaat firmalarının PPY uygulaması ile kaynaklarını daha efektif kullanabilecekleri ve risklerini azaltabilecekleri düşünülmektedir.
Böylece, kaynaklar da kendilerine uygun projelerde daha efektif çalışabilmektedirler. Diğer taraftan, firmalar aynı anda birçok projeyi yürütürken aynı kaynak havuzunu kullanmaktadırlar [24], fakat firmalar proje temelli bir yönetim uygulandıkları zaman genellikle çalışanların kendi projeleri dışında kalan diğer projeler hakkında bilgileri sınırlı kalmaktadır. Bunun sonucu olarak havuzda yer alan kaynaklara bir proje ihtiyaç duyarken diğer projede kullanılmadan durabilmektedir. Hâlbuki PPY vas1tasıyla firmalar bütün projeleri bir bütün olarak yönetebilmekte, bu da kaynaklara farklı projelerin ihtiyaç duyması durumunda bu kaynakların daha efektif kullanılmasını sağlamaktadır [2]. PPY uygulaması sırasında dikkat edilen diğer bir nokta ise proje portföyü oluştururken projeler arasındaki uyumdur. Böylece, benzer bilginin ve kaynağın kullanılabildiği projelerin bir arada yapılması sağlanmaktadır. Bunun sonucu olarak, firmalar aynı kaynaklardan birden fazla projede dönüşümlü olarak yararlanabilmektedirler.

Çizelge 6 incelendiği zaman görüleceği gibi PPY'nin en önemli ikinci etkisinin riskleri azaltmak olduğu görülmektedir. Bu nedenle, PPY'nin karşılaşılan risklerin yönetilmesinde önemli bir etkisi olduğu söylenebilir.

Çizelge 6. Ankete katılan firmalara göre PPY'nin yaptı̆̆g etkiler

\begin{tabular}{|c|c|c|c|c|c|}
\hline Etkiler & Ortalama & $\begin{array}{l}\text { Standart } \\
\text { sapma }\end{array}$ & $\begin{array}{c}\text { PPY } \\
\text { uygulayan }\end{array}$ & $\begin{array}{c}\text { PPY } \\
\text { uygulamayan }\end{array}$ & $\begin{array}{c}\text { P- } \\
\text { değeri }\end{array}$ \\
\hline Kaynakların daha efektif kullanılması & 4,75 & 0,630 & 4,50 & 4,83 & 0,319 \\
\hline Riskin azaltılması & 4,43 & 0,844 & 4,00 & 4,56 & 0,065 \\
\hline Proje Portföyündeki dengenin sağlanması & 4,40 & 0,841 & 4,20 & 4,46 & 0,392 \\
\hline Firma stratejisine uygun hale gelinmesi & 4,30 & 0,822 & 4,00 & 4,40 & 0,186 \\
\hline Belirlenen ortalama maliyeti başarmak & 4,23 & 0,999 & 4,40 & 4,16 & 0,529 \\
\hline Belirlenen ortalama zamanı başarmak & 4,20 & 0,911 & 4,30 & 4,16 & 0,694 \\
\hline $\begin{array}{l}\text { Yöneticilerin takım çalışmasına ve sorumluluk } \\
\text { almaya yönlendirilmesi }\end{array}$ & 4,13 & 1,090 & 4,40 & 4,03 & 0,363 \\
\hline Belirlenen ortalama kaliteyi başarmak & 3,53 & 1,109 & 3,80 & 3,43 & 0,231 \\
\hline Paydaşlar arasındaki iletişimin geliştirilmesi & 2,85 & 1,210 & 3,10 & 2,76 & 0,457 \\
\hline
\end{tabular}

Firmalar sınırsız kaynağa sahip değillerdir, bunun sonucu olarak eldeki kaynakların en efektif şekilde kullanılması firmaların başarısı için büyük önem taşımaktadır. Diğer önemli husus ise, firmalar genellikle eldeki kaynaklara göre çok daha fazla sayıda projeyi bir arada yürütmeye çalışmaktadırlar. Bundan dolayı, birden fazla projenin bir arada yürütüldüğü ortamlarda en önemli sorun bu projelerin en önemlilerin belirlenmesi ve sınırlı kaynağın diğer projeleri zarara uğratmadan efektif olarak kullanılmasıdır [24]. PPY sayesinde firmalar hangi projelerin daha önemli olduğu ortaya çıkarabilirler ve kaynaklarını öncelikli olarak bu projelere yönlendirebilirler. Bu da kaynakların efektif bir şekilde kullanılmasını sağlayacaktır. Ayrıca, PPY uygulayan firmalar daha proje seçim aşamasında eldeki kaynaklarını düşünmekte ve proje seçimlerini eldeki kaynaklarına uygun olarak yapmaktadırlar [2].
Risklerin proje temelli yönetilmesinin risklerin tam olarak yönetmekte yetersiz kaldığı bu nedenle daha geniş bir perspektifle yönetilmesi gerektiği düşünülmektedir. $\mathrm{Bu}$ geniş perspektif risklerin organizasyon düzeyinde ve portföy düzeyinde yönetilmesi olabilir. Organizasyon seviyesinin hiyerarşik anlamda projelere uzak olması nedeniyle risklerin hızlı bir şekilde ortaya çıkarılması ve yönetilmesi imkânsız hale gelmektedir, bu nedenle risklerin organizasyon düzeyinde yönetilmesi risklerin verimli şekilde yönetilmesi için tek başına yeterli olmamaktadır [16]. Portföy düzeyinde risk yönetiminin riskleri yönetmek için en ideal yönetim şekli olduğu düşünülmektedir [27]. Çünkü firmalar bu yaklaşım sayesinde projelerin birbirine olan bağımlılıkları nedeniyle ortaya çıkan riskleri belirleyebilirler ve değişik projeler- 
deki risklerin birbirlerine olarak bağlılıklarını ortaya çıkarabilirler [16]. Olsson [27] risklerin portföy düzeyinde yönetilmesi sayesinde şirketlerin üç düzeyde yarar sağlayacağını söylemektedir. Birinci düzeyde firmalar diğer projelerdeki riskleri inceleyerek riskler konusunda deneyim kazanarak, bu deneyimlerini portföylerinde yer alan projelerin risk yönetimlerinde kullanılabilirler. Risk yönetimde bilginin önemi literatürde yoğun şekilde vurgulanmaktadır. İkinci düzey ise portföy düzeyindedir. Bu düzeydeki yararın elde edilebilmesi için portföyün ortak risklerinin ortaya çıkarılması gerekmektedir. Böylece, firmalar bu riskleri kendileri için avantaj haline getirebilirler, çünkü bir projedeki risk başka bir proje için firsat anlamına gelebilmektedir [1]. Üçüncü düzey ise organizasyon düzeyindedir, firmalar kendi içerisindeki portföyleri birbirleriyle karşılaştırarak bu portföylerdeki ortak riskleri ortaya çıkarabilir. Böylece, firmanın yapısal sorunlarını da görmüş olurlar. Bu nedenle risklerin proje seviyesinde yönetilmesi yerine portföy seviyesinde yönetilmesiyle risklerin çok daha etkili şekilde yönetilebileceği ve projelerdeki risklerin etkilerinin azaltılabileceği görülmektedir.

Yapılan analizler sonucunda elde edilen diğer önemli bir bulgu ise paydaşların arasındaki iletişimin geliştirilmesinde PPY'nin etkisinin sınırlı olduğudur. Hâlbuki engelleyici faktörler içerisinde en önemli faktörün paydaşlar arasındaki fonksiyonel iletişim yetersizliği olduğu ortaya çıkarılmıştı. Bu çerçevede PPY'nin başarılı olabilmesi için ilk olarak paydaşlar arasındaki iletişimin geliştirilmiş olması gerekmektedir, diğer bir deyişle paydaşlar arasındaki iletişim geliştirilmeden PPY'nin başarılı bir şekilde uygulanması mümkün olmamaktadır. Diğer taraftan, PPY'yi uygulamaya başlamak paydaşlar arasındaki iletişimin oluşmasını sağlamamaktadır. $\mathrm{Bu}$ da bize proje portföy yönetimi uygulamasından önce mutlaka paydaşlar arasında iletişimin geliştirilmesi için hazırlıkların yapılması gerektiğini ve proje portföy yönetimi uygulamalarının ise iletişim eksikliğini ortadan kaldırmaya katkısının sınırlı olduğunu göstermektedir.

Yapılan t-test incelendiği zaman proje portföy yönetimini uygulayan ve uygulamayan firmalar arasında proje portföyü yönetiminin etkisi açısından anlamlı bir fark olmadığg görülmektedir. Ayrıca, her ne kadar firmalar PPY'yi uygulamasa bile uygulama sonucunda pozitif etkilerinin olacağını düşünmektedirler. Yine de bu etkiler arasında en büyük görüş farkının riskin azaltılması konusunda olduğu anlaşılmaktadır. Proje portföy yönetimini uygulamayan firmalar proje portföy yönetimi sayesinde risklerle daha iyi mücadele edilebileceğine inanmaktadır. Diğer tarafindan uygulayan firmalar ise proje portföy yönetiminin risklerin yönetilmesinde etkisinin olduğunu düşünmekle beraber bu seviyenin daha sınırlı olduğu görüşündedirler.

\section{SONUÇ (CONCLUSION)}

Firmalar klasik proje yönetimi uygulamaları ile piyasadaki rekabetçi gücünü koruyamamakta ve bunun sonucu olarak yeni bir yaklaşım olan proje portföy yönetimine yönelmektedirler. Fakat, inşaat sektörü incelendiği zaman proje portföy yönetimi uygulamalarının sınırlı olduğu görülmektedir. Bunun en önemli nedenleri ise firmaların proje portföy yönetimini nasıl uygulayacaklarını bilmemeleri ve yararlarını tam olarak idrak edememeleridir. $\mathrm{Bu}$ nedenle, bu çalışmada ankete katılan firmaların görüşleri çerçevesinde Türk inşaat sektöründe PPY uygulamasının başarılı olmasını engelleyici faktörler ortaya çıkarılarak, firmaların daha hazırlık aşamasında bu faktörlere karşı gerekli tedbirleri almasını sağlayacak yol haritalarının oluşturmasına yardımcı olmaya çalışılmıştır. Aynı şekilde, firmaların PPY'den ne beklemesi gerektiği belirlenmiştir. $\mathrm{Bu}$ çalışma sonucunda firmaların PPY uygulaması sırasında başarısını engelleyici en önemli faktörlerin paydaşlar arasındaki fonksiyonel iletişim yetersizliği, paydaşların proje portföy yönetimi uygulamasına adanmışlığındaki yetersizlik ve gerekli eğitimin yetersiz olması olduğu ortaya çıkarılmıştır. PPY'nin başarılı şekilde uygulanmasını engelleyici en önemli faktörlerden birinin paydaşlar arasındaki fonksiyonel iletişim yetersizliğidir, bu nedenle paydaşlar arasındaki iletişim proje portföyün başarılı şekilde uygulanması için çok önem teşkil etmektedir. Diğer bir deyişle, proje portföy yönetimini uygulamak isteyen firmaların mutlaka paydaşları ile iletişimlerini kuvvetlendirmeleri gerekmektedir. Bu amaçla, firmalar paydaşları ile iyi ve uzun süreli ilişkiler kurmayı tercih etmelidirler. Ayrıca, projeler arasındaki iletişim geliştirilmesi de büyük öneme sahiptir. Bu amaçla firmalar bilgi ve iletişim teknolojilerinden yararlanabilirler. Diğer bir önemli unsur ise paydaşların proje portföy yönetimine adanmışlığıdır. Bu adanmışlığı sağlamak ise şirketin üst yönetimine düşmektedir. Diğger bir deyişle, adanmışlık üst yönetimle başlamalıdır. Eğer üst yönetim PPY'ye inanmazsa veya PPY hakkında şüpheleri varsa, PPY uygulamasının başarılı olması mümkün görülmemektedir. $\mathrm{Bu}$ açıdan, PPY uygulamasına başlamadan önce üst yönetimin sahip olduğu şüpheler ortadan kaldırılmalıdır. Diğer aşamada ise alt kademedeki personele PPY'nin önemi ve yararları anlatılarak şirket içerisinde PPY'ye duyulan inanç artırılmalıdır. PPY uygulamayan firmalar açısından bakıldığı zaman en önemli sorunun bu firmaların PPY konusunda yeterli bilgisinin olmaması olduğu görülmektedir. Hatta uygulamayan firmalar bu engellerin aşılmasının zor olduğuna inanmaktadır. Diğer taraftan, uygulayan firmalara baktığımız zaman bu faktörleri önemli engelleyiciler olarak görmeleriyle beraber diğer birçok faktörü daha önemli olarak gördükleri anlaşılmaktadır. Bu da bize PPY hakkında yapılacak çalışmaların sayısının artması ve bunun sonucu olarak bu konudaki bilginin ve bilincin artması ile beraber PPY uygulamas1nın Türk inşaat sektöründe artma olasılığının olduğunu göstermektedir. PPY uygulamasının yararları incelendiği zaman ise en önemli yararların kaynakların daha efektif kullanılmasında ve risklerin azaltılmasında görülmüştür. En az etki ise paydaşların arasında iletişimde olduğu düşünülmektedir. En son olarak, bu çalışmanın kısıtlamalarından bahsedilecektir. $\mathrm{Bu}$ çalışmanın en önemli kısıtlaması katılımcı sayısının sınırlı olmasıdır. Özellikle 
PPY uygulayan firma sayısı anket çalışması için çok s1nırlıdır. Fakat Türk inşaat sektörü düşünüldüğü zaman PPY uygulayan firma sayısı çok azdır. Bu anlamda PPY uygulayan çok sayıda firmaya ulaşmak mümkün olmamıştır. Literatüre bakıldığı zaman bu konu hakkında bilgi üretilmesinin PYY uygulamasının artması için çok önemli olduğu görülmektedir. Bu tür çalışmaların yapılmayıp PYY uygulayan firma sayısının artmasını beklemek ise PYY'nin Türkiye'de uygulanma şansının azalmasına neden olacaktır. Bu nedenle, Türkiye'deki PPY uygulamalarının artması anlamında bu çalışma birçok firmaya yön gösterebilme potansiyeline sahiptir. Daha sonraki aşamalarda ise PYY uygulayan firma sayısının artması ile daha ayrıntılı analizler yapmak mümkün olabilecektir. Ayrıca, bu çalışmada yer alan uygulayan firmalar incelendiği zaman bu firmaların PPY olgunluk seviyelerinin yüksek olduğu görülmektedir. Bu açıdan bulunan sonuçların anlamlı olduğu düşünülmektedir. Diğer önemli kısttlama ise elde edilen kısitlı veri nedeniyle konu hakkında daha derin bilgi sağlayacak analizlerin yapılamamasıdır. Fakat literatür incelendiği zaman bu konu hakkında yapılan çalışmalarda da benzer analizlerin yapıldığı görülmektedir [3, 5]. Yine de PPY uygulamasının artması ile birlikte daha farklı analizlerin yapılması konunun daha derinlemesine incelenmesi açısında önemlidir.

\section{KAYNAKLAR (REFERENCES)}

1. Martinsuo M., "Project portfolio management in practice and in context", International Journal of Project Management, 31(6): 794-803, (2013).

2. Kaiser M. G., El Arbi F., and Ahlemann F., "Successful project portfolio management beyond project selection techniques: Understanding the role of structural alignment", International Journal of Project Management, 33(1): 126-139, (2015).

3. Shehu Z., ve Akintoye A., "Major challenges to the successful implementation and practice of programme management in the construction environment: A critical analysis", International Journal of Project Management, 28(1): 26-39, (2010).

4. Hernández C., Pajares J., ve López-Paredes A., "A portfolio inspired metric for project selection in construction management", Organization, Technology \& Management in Construction: An International Journal, 3(1): 246-268, (2011).

5. De Reyck B., Grushka-Cockayne Y., Lockett M., Calderini S. R., Moura M., ve Sloper A., "The impact of project portfolio management on information technology projects", International Journal of Project Management, 23(7): 524-537, (2005).

6. Rajegopal S., McGuin P., ve Waller J., "Project portfolio management: Leading the corporate vision", Project Portfolio Management, (2007).

7. Young M., ve Conboy K., "Contemporary project portfolio management: Reflections on the development of an Australian Competency Standard for Project Portfolio Management", International
Journal of Project Management, 31(8): 1089-1100, (2013).

8. Elonen S., ve Artto K. A., "Problems in managing internal development projects in multi-project environments", International Journal of Project Management, 21(6): 395-402, (2003).

9. Choi Y. R., ve Shepherd D. A., "Entrepreneurs' Decisions to Exploit Opportunities", Journal of Management, 30(3): 377-395, (2004).

10. Jonas D., "Empowering project portfolio managers: How management involvement impacts project portfolio management performance", International Journal of Project Management, 28(8), (2010).

11. Hermano V. ve Martín-Cruz N., "The role of top management involvement in firms performing projects: A dynamic capabilities approach", Journal of Business Research, 69(9): 3447-3458, (2016).

12. De Brentani U. ve Kleinschmidt E. J., "Corporate Culture and Commitment: Impact on Performance of International New Product Development Programs", Journal of Product Innovation Management, 21(5): 309-333, (2004).

13. Unger B. N., Kock A. Gemünden H. G., ve Jonas D., "Enforcing strategic fit of project portfolios by project termination: An empirical study on senior management involvement", International Journal of Project Management, 30(6): 675-685, (2012).

14. Müller R., Martinsuo M., ve Blomquist T., "Project portfolio control and portfolio management performance in different contexts", Project Management Journal, 39(3): 28-42, (2008).

15. Cooper R., Edgett S., ve Kleinschmidt E., "Portfolio management for new product development: results of an industry practices study", $R \& D$ Management, 31(4): 361-380, (2001).

16. Teller J., "Portfolio Risk Management and Its Contribution to Project Portfolio Success: An Investigation of Organization, Process, and Culture", Project Management Journal, 44(2): 36-51, (2013).

17. Datz T., "Portfolio Management Done Right." $<$ http://www.cio.com/article/2440051/itorganization/portfolio-management-doneright.html>. (18.07, 2016), (2003).

18. Meskendahl S., "The influence of business strategy on project portfolio management and its success - A conceptual framework", International Journal of Project Management, 28(8): 807-817, (2010).

19. Chao R. O., Kavadias S., ve Gaimon C., "Revenue Driven Resource Allocation: Funding Authority, Incentives, and New Product Development Portfolio Management", Management Science, 55(9): 15561569, (2009).

20. Mikkola J. H., "Portfolio management of R\&amp;D projects: implications for innovation management", Technovation, 21(7): 423-435, (2001).

21. Hunt R., Killen C. P., Killen C. P., Hunt R. A., ve Kleinschmidt E. J., "Project portfolio management for product innovation", International Journal of Quality \& Reliability Management, 25(1): 24-38, (2008).

22. Jonas D., Kock A., ve Gemünden H. G., "Predicting project portfolio success by measuring management 
quality-a longitudinal study", IEEE Transactions on Engineering Management, 60(2), (2013).

23. Kendall G., ve Rollins S., "Advanced project portfolio management and the PMO", J. Ross Publishing, Florida, (2003).

24. Fricke S. E., ve Shenbar A. J., "Managing multiple engineering projects in a manufacturing support environment", IEEE Transactions on Engineering Management, 47(2): 258-268, (2000).

25. Cooper R. G., Edgett S. J., ve Kleinschmidt E. J., "Benchmarking Best NPD Practices-I", ResearchTechnology Management, 47(1): 31-43, (2004).
26. Teller J., ve Kock A., "An empirical investigation on how portfolio risk management influences project portfolio success", International Journal of Project Management, 31, (2013).

27. Olsson R., "Risk management in a multi- project environment: An approach to manage portfolio risks", International Journal of Quality \& Reliability Management, 25(1): 60-71, (2008). 